\title{
PINTANDO A MÁQUINA \\ LA INFLUENCIA PICTÓRICA EN LA OBRA LITERARIA DE FERNANDO DEL PASO
}

Para Margit Frenk

\author{
Es tal la intranquilidad básica \\ de este hermoso ejemplo de la \\ modernidad narrativa hispanoamericana, \\ que sólo puede recordarnos \\ a un Gaudí centuplicado \\ Marco Antonio Montes de OCA
}

El interés que las artes plásticas despiertan en la literatura es de viejo cuño. Ya Simónides de Ceos, en el siglo v a. C., se refirió a la poesía como si se tratara de un cuadro hablado y a la pintura como de un poema mudo. Aforismos, por lo demás, que serán retomados una y otra vez a lo largo de los siglos. Está también el auge de la técnica llamada ekphrasis, en la que la palabra se inspira directamente en lo antes realizado por el arte espacial. Más tarde, surge la técnica de la enargeia, que consistía en un estilo de descripción que debía competir con lo transmitido en una pintura. Así, con altas y bajas, esta relación dio vuelta a la página del siglo xx con los caligramas de Apollinaire, que no se contentaban con referirse a una realidad plástica, sino que ellos mismos contenían en su ser ese aspecto dibujado que reproduce con palabras al objeto aludido, en un intento por hacer más intrínseca la relación entre los dos mundos artísticos. La narrativa, por supuesto, no se ha quedado a la zaga.

En las décadas de 1970 y 1980, Del Paso escribió en forma asidua en distintos medios periodísticos: El Día, Proceso, Revista de la Universidad, Vuelta ${ }^{1}$. Entre la gran diversidad de temas abordados, encontramos alrededor de una treintena de artículos dedicados a la pintura. Este material muestra la mirada profundamente interesada y sensible de Del Paso ante las artes plásticas, y en particular la pintura contem-

${ }^{1}$ Estoy por concluir la compilación de la amplia obra periodística de Del Paso. 
poránea. Habría, además, que hacer un señalamiento fundamental: el escritor mismo ha incursionado por los caminos de esa manifestación artística, primero como dibujante, después como pintor. Este hecho incide sin duda en su percepción de la obra pictórica de la que habla: no se trata únicamente de alguien atraído por un arte diferente al suyo, sino de alguien que trabaja con los dos lenguajes. Y añadiría que incide también en su creación literaria. No es difícil suponer que muchas de sus descripciones imbuidas de texturas plásticas se hayan desarrollado a partir de una concepción artística propia de quien se dispone a mezclar colores y a esbozar formas con la ayuda de un pincel. En todo caso, esa es la impresión que el lector tiene ante múltiples pasajes de la literatura delpasiana.

Estos artículos periodísticos referentes a la pintura presentan algunos rasgos generales. Para empezar, puede decirse que casi todos los textos tienen como origen la reseña de una exposición presentada en Londres o, excepcionalmente, en París. Salvo unos cuantos dedicados a la obra de pintores de otro tiempos (Reynolds, Fuseli², Daumier), es indudable una mayor inclinación por las producciones experimentales de este siglo: el surrealismo, el fauvismo, el futurismo, el expresionismo y todos esos ismos tan propositivos, así como el arte abstracto, el pop y el op. Esto, por lo demás, no tiene nada de sorprendente si pensamos en las propias tendencias vanguardistas de la literatura de Del Paso. Pero volvamos a los artículos. Es común que, al lado de puntualizaciones sobre los cuadros y de datos específicos acerca del pintor en cuestión, aparezcan reflexiones sobre diferentes aspectos de la génesis y desarrollo de su obra. Esta afirmación es aún más pertinente en el caso de textos consagrados a alguna escuela (futurismo, simbolismo, romanticismo), donde el escritor medita sobre principios, propuestas, ideologías, resultados obtenidos y la ubicación de la corriente dentro de la historia del arte. No falta la presencia de artículos que tratan de escritores que, como el propio Del Paso, acudieron a la plástica como medio expresivo (Víctor Hugo, Chesterton, Blake), ni los que se ocupan de un arte más utilitario (la ilustración de portadas de discos y la creación de carteles, se trate o no de imitaciones de grandes movimientos artísticos, donde entra-

2 Ésta es la muy extendida traducción inglesa del nombre Füssli. El pintor suizo, que estableció su residencia en Inglaterra, es el autor de una obra que, junto con la de El Bosco, fue referencia obligada de los surrealistas (José PIERre, "El surrealismo", en Historia de la pintura, Asuri, Bilbao, 1989, t. 4, pp. 751-782; y ANTONio Bonet CoRREA, "La pintura surrealista: etapas y problemas", en El surrealismo, Cátedra, Madrid, 1983). En "Henry-Fuseli: carne de siquiatra" (El Día, 24 de abril de 1974, p. 4), Del Paso habla de la obsesión del pintor por la muerte, la violencia, el sexo, el sadismo y lo sobrenatural, y señala la admiración de Freud hacia su cuadro más conocido, "La pesadilla". Por otra parte, en la obra de este pintor encontramos una vez más la reunión de la plástica y la literatura: Fuseli, gran lector, recreó en sus telas historias y personajes como Macbeth, David y Goliath, Dante en el infierno. 
ría Aldridge, por ejemplo). Encontramos también reflexiones sobre aspectos curiosos o polémicos: el futurismo como hervidero de ideas que otras escuelas desarrollarían de manera cabal más tarde; Inglaterra como cuna de movimientos que alcanzarían su clímax en otros países; dificultad eventual para distinguir entre una verdadera expresión artística y una tomadura de pelo; injustificación moral del precio alcanzado por piezas artísticas; debilidad teórica de algunos críticos de arte; torpeza en la presentación de algunas exposiciones, etc. Entre los nombres encontramos a Paolozzi, Gris, Miró, Tàpies, Louis, Klee, Turner, Folon, Ernst, Villon, Matta. No falta incluso un artículo dedicado a un artista hoy poco conocido, "El inimitable Tom Keating” (El Día, 13 de junio de 1977, p. 5), famoso en la Inglaterra de la década de los setenta por sus magistrales falsificaciones de artistas consagrados, las cuales ocasionaron -y quizá sigan ocasionandoque los especialistas se rompieran la cabeza para identificarlas y sacarlas del circuito artístico. Está también la presencia de artistas, y no pintores, como el fotógrafo y creador de objetos Man Ray, integrantes de alguna escuela de gran trascendencia. Mención aparte merece el hermoso texto "Homenaje a Tériade" (El Día, 22 de octubre de 1975 , p. 4), ese gran editor que fundó revistas como Cahiers d'Art, Minotaure y Bête Noire, perfeccionó las artes de la litografía y la imprenta, y reunió alrededor suyo a personalidades como Picasso, Miró, Matisse, Gris, Giacometti, para, entre otras cosas, reconciliar la poesía y la pintura. Así, entre sus publicaciones se cuentan Jazz — con texto y dibujos de Matisse-, Circo - escrito e ilustrado por Chagall-y el Ubu Roi de Jarry con ilustraciones de Miró.

Aun cuando estos artículos - y la obra periodística global- tienen una importancia intrínseca que hace que se sostengan por sí mismos, aquí nos interesan en relación directa con su producción literaria: los lazos de unión que se establecen entre estos dos ámbitos creativos; las líneas que se encuentran en uno y otro lado; la afinidad entre los artistas elegidos para las notas y su propia obra creadora.

La incansable búsqueda lingüística y estilística que el escritor demostró en José Trigo ${ }^{3}$, se transformó en Palinuro de México ${ }^{4}$, para dar cabida al predominio de la imaginación visual. En una entrevista que concedió a Ignacio Trejo Fuentes en 1980, Del Paso habló, entre otras cosas, de dos aspectos que me interesa destacar: el primero se refiere a la turbadora extensión de algunas novelas publicadas en ese momento, entre las que se incluye Palinuro, obra de más de seiscientas páginas: "de alguna manera, agregarle espacio físico permite decir, contar, crear más cosas, extenderse, regodearse, pintar murales, ahondar

${ }^{3}$ Sigo la 2a ed., Siglo XXI, México, 1967.

${ }^{4}$ J. Mortiz, México, 1980. 
en los temas y en los personajes..."5. El otro remite a la relación literatura/pintura: "En mi segunda novela, según creo, el lenguaje está más bien puesto al servicio de la imaginación plástica, de la imaginación surrealista, tanto en el sentido literario como plástico" (p. 9).

Ya antes, en 1979, había dicho a Jorge Ruffinelli que el surrealismo era quizá la mayor influencia en Palinuro y, añadió, "no solamente la literatura surrealista, sino incluso la pintura surrealista" ${ }^{6}$. Los nombres de Magritte y Delvaux, presentes en entrevistas posteriores, aparecen quizá por primera vez en esta plática con el crítico uruguayo.

El interés por "pintar murales" con las herramientas de la literatura y las declaraciones explícitas de la deuda de Palinuro con la tradición y el lenguaje de la pintura, nos dan la pauta de la importancia real de un mecanismo presente ya en José Trigo, explorado amplia y profundamente en Palinuro, incluido en muchísimas páginas de Noticias del Imperio ${ }^{7}$ y en no pocas de Linda 67. Historia de un crimen $^{8}$. No se trata, pues, de un elemento abordado con un espíritu simplemente experimental, sino de una constante que forma parte inherente de la visión del mundo del escritor. Que Del Paso hable de manera explícita de los pintores surrealistas no es gratuito: su admiración, respeto, gusto, devoción incluso, por los pintores de esa escuela -con cierta inclinación por algunos de ellos, como Magritte-, se deja ver claramente en gran parte de su obra hemerográfica y en muchos de sus dibujos ${ }^{9}$. Ahora bien, el que en las entrevistas haya hablado de esa escuela no excluye de sus novelas un sinfín de alusiones, expresas o tácitas, a un número impresionante de pintores y pinturas de todas las épocas. Y esto nos lleva directamente a presentar la tesis de este artículo: en el proceso creador de Del Paso, en el que una de las

5 "Entrevista con Fernando del Paso", La Semana en Bellas Artes, 1980, núm. 138, p. 7; las cursivas son mías.

6 "Entrevista con Fernando del Paso", Vuelta, 1979, núm. 37, p. 47.

7 Diana, México, 1987.

8 Plaza y Janés, México, 1995.

${ }^{9} \mathrm{Me}$ atrevería a poner al manierismo - que puede tomarse como una especie de antecedente del surrealismo- en un lugar importante. Y no me refiero sólo a la prosa, sino también a su creación plástica. Piénsese, por ejemplo, en la imagen que sirvió para ilustrar la portada de Palinuro en su 1a ed. (J. Mortiz, 1980). Ahí se ve la intención totalizadora de Del Paso, que ilustra lo que el lector va a encontrar en la novela. En un pasaje de "La «Beatlemanía» ilustrada", El Día, 7 de febrero de 1974, p. 10, artículo que Del Paso dedica a Aldridge, se pueden ver, me parece, algunos de los vasos comunicantes de los diferentes ámbitos creativos del escritor mexicano: "En muy pocos artistas se han conjugado con tal abundancia, y en forma tan obsesiva, las principales constantes del arte manierista... y, más que nada, el deseo de decirlo todo... nadie, como Alan Aldridge, ha sabido expresar en forma tan maravillosa esa extraña combinación de histeria, exceso, amor y dulzura que caracteriza a nuestra época a partir de los Beatles”. Descripción más que pertinente para la obra artística del autor de Palinuro. 
características más notables es su permanente juego intertextual, la pintura ha ocupado un lugar destacado.

La intertextualidad implica inevitablemente la participación del lector en la construcción del texto. No es extraño, pues, que cuando Del Paso se ha referido a sus novelas haya señalado la necesidad de un lector "macho", según la terminología cortaziana ${ }^{10}$. Michael Riffaterre ${ }^{11}$, por su parte, menciona una especie de dialéctica de la memoria entre el texto que el lector descifra y los textos que el lector recuerda. Esta aseveración, por supuesto, resulta válida para los dos tipos de intertextualidad pictórica que me interesa destacar en estas páginas.

Cuando Del Paso cita el nombre de un pintor o de un cuadro para expresar lo que quiere, con o sin desarrollo subsecuente, está pidiendo un conocimiento del lector, por mínimo que sea, que haga posible que el texto se llene de sentido. Si no, y tal como lo afirma Speratti en su trabajo sobre Cortázar, el pasaje queda reducido a un catálogo sin ilustraciones ${ }^{12}$. Veamos un par de ejemplos. A unas cuantas páginas de haber dado inicio la novela, Palinuro, al narrar trozos de vida del tío Esteban y de la relación estrecha que siempre tuvo éste con el mundo de la medicina, dice:

${ }^{10}$ Del Paso mostró un cambio de opinión en dos momentos diferentes. En la entrevista con Trejo Fuentes, señaló la facilidad de su segunda novela en relación con la primera: "Entiendo que para leer José Trigo se necesita ser lector «macho» en el sentido en que lo definía Cortázar. Pero pienso que el caso de Palinuro de México es distinto, y que basta con ser un lector ya acostumbrado a la complejidad y la riqueza de muchas de las novelas modernas, para disfrutar, entender y recrear mi segundo libro" (p. 7). Seis años después, diría a Fátima Cabañas, y con toda razón, que el lector de Palinuro de México tenía que ser "macho" ("Fernando del Paso: entre Palinuro y Carlota”, El Semanario Cultural de Novedades, 27 de abril de 1986, núm. 210, p. 2).

11 "Syllepsis", Critical Inquiry, 6 (1980), 625-638.

12 E. S. Speratti-Piñero, "Julio Cortázar y tres pintores belgas: Ensor, Delvaux, Magritte”, NRFH, 24 (1975), p. 553. Cortázar, además de introducir el mundo de la plástica en sus textos, hizo análisis de otras obras literarias en las que se presenta este rasgo. Véase, por ejemplo, "La urna griega en la poesía de John Keats", en Ensayos críticos 2, Alfaguara, México, 1994, donde revisa la influencia del mundo helénico en la poesía del inglés y muestra cómo "su temperamento lo aleja de una posible influencia poética griega y lo entrega en cambio rendidamente a la admiración por la plástica. Entre la palabra y la forma griegas, va Keats hacia la forma que se le ofrece sin la mediatización degradante de las traducciones... Cuando, en la Urna griega, alcance él su cercanía más admirable con el genio helénico, el verso estará allí para celebrar figuras marmóreas, la imaginaria obra maestra de un anónimo cincelador inspirado" (p. 39). Cortázar también incursionó en las artes plásticas. En "Chile vencerá" (El Día, 9 noviembre de 1974, p. 5), Del Paso recuerda que el argentino colaboró en un festival en pro de la democracia de aquel país: "Pero no se trató de una declaración, de un cuento, una carta o un poema, sino de un cuadro... Es una pintura abstracta, a base de manchas, acudiendo un tanto al azar, pero llena de alegría y ritmo". 
Fueron tantas... las ilustraciones y las láminas que pasaron por sus manos, desde las danzas de la muerte de Holbein de Basilea que inspiraron a Saint-Saëns y a Glazunof, hasta los Apestados de Jaffa del Barón Gros, pasando por todos los estropeados de El Bosco, los dentistas de Van Ostade, los poseídos de Van Noort, los barberos cirujanos de Teniers, los pestíferos de Poussin, los leprosos de Hans Burgkmair, los ciegos de Brueghel y los tiñosos de Giovanni della Robbia, que el tío Esteban... llegó a pensar y a actuar como un médico de verdad... (p. 20).

Más adelante, en el capítulo 4, Palinuro habla del carácter angelical de su prima Estefanía y describe aquella vez en que este ángel de mentira tuvo alas de verdad cuando participó en una representación teatral:

Alas pardas con ojos de pavorreal como los ángeles pintados por Filippo Lippi, y alas blindadas como las alas de los ángeles de Perugino, tal como quería el primo Walter.

Alas doradas como las alas del arcángel Gabriel pintado por Masolino da Panicale, y alas en explosión como los ángeles del Tintoretto, tal como se le ocurrió a la tía Luisa.

Alas grises como las alas de los ángeles que pintó El Greco, según pensó la abuela Altagracia.

Y alas, en fin, como las que diseñó el tío Esteban para Estefanía, en un intento por darle gusto a todos, y que en todo caso se parecían a las alas de los ángeles de la Anunciación de Mónaco, y de los ángeles músicos de Memling, y que tenían franjas amarillas, moradas, blancas, lilas, rojas, verdes, rosas y azules, como si estuvieran forradas con la piel de una cebra tecnicolor (p. 83).

Puede advertirse que en estas listas aparecen nombres de pintores - en la primera se cuelan de paso dos músicos, rasgo típico del prurito de exhaustividad del escritor-, al lado de algunos de los personajes que pueblan sus telas. Si bien muchos de los artistas resultan bastante conocidos, otros no son tan fáciles de ubicar. Y, siguiendo de nuevo las palabras de Speratti sobre Cortázar, aun cuando todos los nombres resultaran familiares al lector, se necesitaría que éste conociera mínimamente una de sus obras para tratar de imaginar, por lo menos a nivel de forma y colorido, lo que Palinuro está expresando. Aquí también, como en el caso del escritor argentino, se puede pensar en cierta tendencia, consciente o inconsciente en el autor, a hacer que el lector establezca un tipo diferente de relación con la obra: una relación activa que entre otras cosas incluye una pesquisa, aunque sea rápida. Después de todo, Del Paso ha elegido siempre la vía de la investigación constante y exhaustiva para la elaboración de sus obras. ¿Por qué no llevar a su lector, entonces, por el mismo camino? Y esto, sin duda, marca la pauta de una especie de complicidad muy estrecha entre lector y texto. 
Pero volvamos a las listas mencionada por Palinuro. En ellas resulta notable el número de pintores pertenecientes a la escuela flamenca (Holbein, El Bosco, Va Ostade, Van Noort, Teniers, Burgkmair, Brueghel, Memling), lo cual, por supuesto, tampoco es gratuito. Debemos tener presente que existe toda una tradición escatológica en esta pintura, y que Palinuro de México participa ampliamente de este rasgo. En primer lugar, y de manera más que evidente, está la importancia de la medicina y del cuerpo humano, no sólo en su aspecto externo, marmóreo y bello, sino, y sobre todo, en su parte interna, que involucra vísceras, sanguinolencias, secreciones. En segundo lugar, esta novela se coloca en la filiación carnavalesca en la que Rabelais, influencia incontestable en Palinuro de México, es figura señera. Y el carnaval, como bien sabemos, cuenta al mundo de la escatología entre sus elementos primordiales. Es, pues, un mismo orden de ideas en el que el cuerpo grotesco ocupa un lugar de primera línea. Ahora bien, esa misma carnavalización, que también incluye la yuxtaposición de elementos contrarios como uno de sus rasgos característicos, nos da la pauta para proponer una interpretación de la otra línea fundamental de estos listados, compuesta por pintores renacentistas: flamencos y renacentistas representan concepciones artísticas, si no opuestas, sí muy diferentes entre sí. Mientras los primeros se detienen en los "horrores" del hombre, los segundos se regodean en su belleza plástica. Otra explicación, que vendría a completar la anterior, es mucho más simple: dado el tema de que se trataba, qué mejor que recurrir a los artistas del Renacimiento, especialmente hábiles en el arte de pintar ángeles. Pero aquí habría que hacer un señalamiento: en la obra de Del Paso, la belleza renacentista está matizada con el tecnicolor, porque el pop es otra de las grandes líneas del interés presentes en Palinuro.

Resulta claro que estas citas de Palinuro se enriquecen notablemente a la luz de ese imaginario plástico del que el personaje habla. Digamos que texto e imagen se encuentran estrechamente relacionados y se requieren mutuamente para poder transmitir de manera cabal el mensaje que se desea. El lector, por supuesto, puede darse por satisfecho con lo que logra aprehender del texto escrito. Es, a fin de cuentas, una lectura posible. Pero no debe descartarse una idea, me parece, primordial: la presencia de estas listas de nombres tiene una intención artística que va mucho más allá de ese afán enciclopedista del que se ha acusado al autor de Palinuro de México, y no puede negarse que, a los ojos del lector, el texto adquiere matices diferentes cuando le es posible aunarlo a las imágenes evocadas por los cuadros.

$\mathrm{Al}$ principio de estas páginas mencioné las declaraciones de Del Paso sobre la pintura surrealista como un ascendiente importante en el mundo de Palinuro. A la luz de un artículo aparecido en El Día (16 de enero de 1974), de título "Magritte, o la búsqueda de un rostro", 
podemos entender con mayor claridad estas afirmaciones del autor. En el texto periodístico, Del Paso habla del matiz sobrenatural contenido en gran número de cuadros de Magritte - y yo añadiría también en los de Delvaux, Dalí y De Chirico, por no mencionar sino a algunas presencias muy visibles en la novela. Ese matiz sobrenatural no depende de la irrealidad de un objeto o de un ser, sino de la "irrealidad creada por las «relaciones» absurdas de objetos reales, concretos y tangibles, situados en un contexto alucinante". En efecto, Palinuro de México, así como largos pasajes del soliloquio de Carlota en Noticias del Imperio, deben mucho a esa imaginación en la que el deslumbramiento se logra a partir de asociaciones inhabituales. Imágenes como "las ilusiones... eran pedazos de estrellas zozobrados en las atarjeas" (Palinuro, p. 291) o "voy a dar a luz a un enjambre de mariposas negras" (Noticias del Imperio, p. 421) se encuentran construidas sobre esa lógica.

Los surrealistas, como todos los demás pintores y escuelas incluidos en las novelas de Del Paso, aparecen en las dos modalidades de intertextualidad que aquí analizo. Para esta escuela resulta interesante detenerse en el lenguaje que adquiere visos plásticos, por la señalada influencia del surrealismo pictórico en Palinuro de México. Y con esto no me limito a seguir lo declarado por el autor, sino que hago una afirmación evidente para cualquier lector de la novela. Habría que considerar, además, y tal como apunta Antonio Bonet Correa, la interrogante acerca del grado de autonomía de la pintura surrealista con respecto a la literatura, hecho que plantea la unión - ¿inseparable?de imagen y palabra. Por lo demás, debemos recordar que el surrealismo, desde sus inicios, "consideró que el arte, lo mismo que la literatura, debía situarse «más allá de toda consideración ética o estética» (Breton), sobrepasando lo meramente formal" (p. 10).

Pero antes, detengámonos un momento en Magritte, pintor profundamente interesado en la relación de los objetos y las palabras. Como dice Del Paso, una de las verdades que Magritte aprendió del mundo fue que "las cosas no son sus nombres, o puesto en otra forma, que los nombres no son sus cosas" ${ }^{13}$. El pintor belga ${ }^{14}$, en efecto, realizó algunas creaciones en las que combina imágenes con textos. Las más de las veces, aparecen palabras asociadas a figuras que no corresponden (por ejemplo, el famoso cuadro "La clave de los sueños", en el que se presentan seis objetos totalmente comunes y cotidianos, acompañados por una palabra que no tiene ninguna relación patente con ellos - al famoso bombín negro, por ejemplo, le pone la mención "La Neige"), otras veces, la palabra sí corresponde,

13 "Magritte, o la búsqueda...," p. 11.

${ }^{14}$ Quien, por lo demás, luchó por imponer nuevas maneras de ver lo familiar, actitud que puede identificarse con la búsqueda de lector activo, aunque, claro, en este caso se busque un espectador activo. 
pero se niega esa relación (véase el igualmente famoso "El viento y la canción", la inmensa pipa del tamaño de casi toda la tela y que incluye la leyenda: "Ceci n'est pas une pipe"). Lo que Magritte hizo fue reunir imágenes y palabras, ya que, pensaba, ambas compartían la misma sustancia ${ }^{15}$. Y lo hizo, además, señalando siempre cómo la percepción puede ser relativa, y planteando que la realidad puede ser enigmática incluso en lo aparentemente más banal, como es el caso de este cuadro, donde título, imagen y leyenda nos conducen a una especie de enredo de los sentidos. Además, como exponente del surrealismo, Magritte no menospreció un concepto clave: no por nada el título del primer cuadro menciona al "sueño". Ahora bien, así como este pintor sostuvo que una función de la pintura era hacer visible la poesía, en la segunda novela de Del Paso se llega a una idea similar, aunque los elementos ocupan lugares distintos: la poesía puede también hacer visible a la pintura.

Del Paso, como Magritte, se divierte en Palinuro de México, con esa posibilidad de romper la relación de las palabras y las cosas, tanto en pasajes "pictóricos" como en otros que no buscan tal efecto. En fragmentos de la descripción que Palinuro hace de su amada prima Estefanía, alude a un juego en el que renombraban al mundo: "Porque si bien yo me encerré alguna vez dentro de un año entre dos febreros locos y besé el pezón húmedo de su olvido derecho y me reflejé en sus triunfos azules, eso fue posible gracias a que esa única vez sus pechos se llamaron olvidos, sus muslos febreros y sus ojos triunfos" (p. 71) ${ }^{16}$. Juego voluntario de los personajes que en otra sección de la novela se hará aparentemente involuntario: "No entiendo -le dije a mi prima-. Antes, mis sueños han sido siempre buenos o malos, agradables o desagradables. Pero anoche todo fue distinto: tuve sueños puntiagudos, sueños rojos, sueños ácidos. No entien-

15 Suzi Gablik, Magritte, New York Graphic Society, Connecticut, 1970, p. 139.

16 Ya en otros trabajos he dicho que con Del Paso es imposible hacer generalizaciones. La presencia de la pintura es muy fuerte en Palinuro, pero lo mismo puede decirse de otros campos que vienen a insertarse en la novela. La literatura, por supuesto, también tiene papel de primera importancia. En una descripción de Estefanía que se quiere hasta cierto punto conclusiva (nada, en Palinuro, es conclusivo; nada, en ninguna de las tres primeras novelas, lo es: Del Paso está en contra de la "fijación" del mundo), se dice: "En pocas palabras, y siempre alta y delgada, con el amor desarmado y prendido a sus pechos como en una pintura de Watteau, hermosa como la Herejía descrita por Winckelmann o como la Bella Rosina de Wietz desnuda y contemplando un esqueleto colgante, misteriosa como Berenice y Ligeia, y con su nombre, Estefanía, escrito en su frente..., Estefanía fue un ser donde siempre fue posible verse de cuerpo entero" (p. 72). Aquí las citas pertenecen a la pintura, a la literatura, a la historia del arte, y no se circunscriben a los nombres de los artistas, sino que se extienden también al de los personajes. Un solo mecanismo de inclusión de préstamos al tejido escritural de Palinuro, pero diferentes niveles de abstracción del préstamo. No es lo mismo hablar de la pintura de Watteau en términos generales, que de dos de los personajes femeninos de Poe. 
do..." (p. 441), cuando los adjetivos desaparecen para más tarde caer de manera errónea y sorpresiva sobre los sustantivos que no debían calificar en un alarde de imaginación que tiene justamente el afán de romper con las asociaciones inmediatas y fáciles del lector (cap. 19).

No resulta fácil decir el número de veces que se habla de los sueños en las obras de Del Paso. Sirva de muestra el capítulo 2 de Palinuro, en el que se dedican largas páginas a describir los sueños de los personajes que habitan una casa de la colonia Roma, y sobre todo los de Palinuro y Estefanía. Y por si la descripción misma no fuera suficiente para recrear la atmósfera tan peculiar del mundo onírico, el narrador nos informa que esos dos personajes tenían, además, la capacidad para intercambiar sus sueños:

Y tres y cuatro recámaras hacia la derecha respectivamente, y sesenta años antes y sesenta años veinte días antes, también respectivamente, a diez metros uno del otro en el espacio, pero a unos milímetros, a unos cuantos granos de arena y de tiempo de bañarse en el mismo mar y en el mismo sueño, Estefanía y Palinuro dormían y soñaban. Dormía Palinuro, soñaba Estefanía. Dormía Estefanía, soñaba Palinuro (p. 41).

En este mundo de los sueños, aunque no se trate sólo de los que se describan como tales en las páginas de la novela ${ }^{17}$, Del Paso hará suya la propuesta de Magritte, y nos encontramos con descripciones que asocian términos inusuales, como puede observarse en la cita anterior. Y de la misma manera hará que sus personajes hablen echando mano de imágenes, no sólo profundamente surrealistas, sino de un surrealismo que remite a producciones de la plástica: "el médico es el mago que te saca un labio de un pecho, un pecho de un codo, un codo de una barriga, una barriga de una nalga y una nalga de una nariz... No, perdón, es al revés: una nariz de una nalga. Eso sí está claro, supongo..." (p. 55) dice Palinuro a Palinuro durante el primer encuentro del personaje desdoblado. Y aunque quizá haya otros pasajes que evoquen de manera plena el cuadro de Magritte intitulado "La violación”, es difícil no ver en este juego de desplazamientos corporales anunciado por uno de los Palinuros, el mismo que el belga realizó al incorporar una cara en el torso desnudo de una mujer.

Y a Magritte recuerda el siguiente pasaje, donde vemos cómo Palinuro, describiendo incansable, amorosa y carnavalescamente a Estefanía, recorre el lienzo geográfico de su hermosa prima: "las pecas parecían emigrar de sus hombros y juntarse en la espalda formando

${ }^{17}$ En el mismo cap. 4 que Palinuro dedica a Estefanía, y en un contexto no onírico, hay una de esas asociaciones que buscan abolir las fronteras de la lógica para dar libre cauce a la "gran iluminación profana", como diría Bretón: "A la salida me fui al bar del Hotel Alameda para matar el tiempo, tomé varios Tom Collins y a los quince minutos me sentí dos horas y seis cerezas más joven” (p. 75). 
continentes adventicios que eran como las sombras de mariposas inmóviles y con las alas extendidas flotando muertas a unos milímetros de su piel" (p. 76).

En este caso, ¿sería demasiado aventurado decir que la última parte de la descripción, que habla de una mariposa flotando a unos cuantos centímetros de la piel, debe algo al cuadro de Dalí donde la omnipresente Gala flota, junto con el agua del mar, a unos cuantos centímetros de la faz de la tierra? ("Leda atómica"). Como puede verse, éste es un ejemplo de la segunda categoría intertextual a la que me referí al inicio de esta sección. En esta descripción de la prima Estefanía, Del Paso no habla de ningún pintor ni de ningún cuadro. Lo que hace es adoptar un lenguaje de texturas, rasgos y matices indudable y felizmente inoculado por una estética plástica.

En este segundo tipo de intertextualidad encontramos también muchos momentos de las novelas de Del Paso en los que algún cuadro, o cuadros, sirven como idea generadora del pasaje. Veamos un ejemplo de este tipo en el que la inspiración plástica no proviene del surrealismo. El capítulo 11 de Palinuro de México, "Viaje de Palinuro por las Agencias de Publicidad y otras Islas Imaginarias", está dividido en diferentes secciones. En una de ellas, de título "Cosmopapagonía", Palinuro, en plena iniciación en la "Publicidad Poética" y equipado con un estuche para hacer uno mismo sus comerciales, imagina uno de papas fritas en el que hay una viejita de pelo blanco, sentada en una mecedora y en una habitación donde están colgados un cuadro de un general y otro, bordado en punto de cruz, que representa unos molinos de viento holandeses. Aquí, por supuesto, la imagen de partida es el cuadro "Arreglo en gris y negro no. 1, retrato de la madre del artista", de Whistler, aunque la escena evoca sobre todo a la versión "pop" del mismo cuadro. En la novela, Palinuro hace que la viejita coma papas fritas; entonces:

Un ligero, ligerísimo crack se escucha en alguna parte... De pronto, los tulipanes del cuadro se estremecen con un escalofrío y se estremece la espuma sabia de los bigotes del general. La viejita se ha llenado la boca de papas fritas: cinco, seis, diez papas al mismo tiempo, y se mece ahora al ritmo de sus mandíbulas. ¡Crack! ;crack! ;crack!, se oye por dondequiera, y el general y los molinos de viento comienzan a pendulear peligrosamente (p. 229).

Por lo demás, la introducción de la onomatopeya - recurso desarrollado plenamente en la sección "Palinuro en Productolandia"-, recuerda algunos cuadros de Roy Lichtenstein. Y para este caso también podríamos remitirnos a un artículo periodístico, "El arte sin chiste y el chiste del arte"18, donde el escritor reseña una exposición de

${ }^{18}$ El Día, 13 de junio de 1973, p. 11. 
caricaturas cuyos temas son cuadros famosos de los principales movimientos del arte moderno: "Un pintor del siglo xvi, equivalente renacentista de Andy Warhol, pinta un cuadro de una olla humeante que dice: «Zuppa di Pomodoro». Y al famoso cuadro «WHAAM!» de Lichtenstein, se le rompen las cuerdas de las que cuelga (SNAP!) y cae al suelo con gran estrépito (CRUNCH!)". Literatura y periodismo, como puede verse, comparten humor e intereses.

Es tan abundante y variado el material pictórico que Del Paso utiliza en su obra, que, por supuesto, estas páginas no tienen la menor intención de agotar siquiera una de las vetas que nos ofrecen. Las novelas de Del Paso no sólo se oyen gracias al uso recurrente de una prosa de sonoridad poética, sino que también se ven. No puedo imaginar una lectura que no responda ante esta avalancha incansable de colores y formas, de volúmenes y perspectivas, que cubren una amplia gama de presentaciones dentro del texto: desde la presencia explícita de palabras que remiten simple y llanamente a colores, hasta ese lenguaje que pinta cuadros a medida que se va deslizando por la hoja de papel.

Elizabeth Corral PeÑa 